University of Nebraska - Lincoln

DigitalCommons@University of Nebraska - Lincoln

\title{
Estimating crop biophysical properties from remote sensing data by inverting linked radiative transfer and ecophysiological models
}

\author{
K. R. Thorp \\ USDA-ARS, kelly.thorp@ars.usda.gov
}

G. Wang

University of Arizona

A.L. West

University of Arizona

M.S. Moran

USDA-ARS

K.F. Bronson

USDA-ARS

See next page for additional authors

Follow this and additional works at: https://digitalcommons.unl.edu/usdaarsfacpub

Thorp, K. R.; Wang, G.; West, A.L.; Moran, M.S.; Bronson, K.F.; White, J.W.; and Mon, J., "Estimating crop biophysical properties from remote sensing data by inverting linked radiative transfer and ecophysiological models" (2012). Publications from USDA-ARS / UNL Faculty. 1173. https://digitalcommons.unl.edu/usdaarsfacpub/1173

This Article is brought to you for free and open access by the U.S. Department of Agriculture: Agricultural Research Service, Lincoln, Nebraska at DigitalCommons@University of Nebraska - Lincoln. It has been accepted for inclusion in Publications from USDA-ARS / UNL Faculty by an authorized administrator of DigitalCommons@University of Nebraska - Lincoln. 


\section{Authors}

K. R. Thorp, G. Wang, A.L. West, M.S. Moran, K.F. Bronson, J.W. White, and J. Mon 


\title{
Estimating crop biophysical properties from remote sensing data by inverting linked radiative transfer and ecophysiological models
}

\author{
K.R. Thorp ${ }^{\text {a,* }}$, G. Wang ${ }^{b}$, A.L. West ${ }^{\text {b }}$, M.S. Moran ${ }^{\text {c }}$, K.F. Bronson ${ }^{\text {a }}$, J.W. White ${ }^{\text {a }}$, J. Mon ${ }^{\text {a }}$ \\ a USDA-ARS, U.S. Arid Land Agricultural Research Center, 21881 N Cardon Ln, Maricopa, AZ 85138, United States \\ ${ }^{\mathrm{b}}$ University of Arizona, Maricopa Agricultural Center, 37860 W Smith-Enke Rd, Maricopa, AZ 85138, United States \\ c USDA-ARS, Southwest Watershed Research Laboratory, 2000 E Allen Rd, Tucson, AZ 85719, United States
}

\section{A R T I C L E I N F O}

\section{Article history:}

Received 29 March 2012

Received in revised form 17 May 2012

Accepted 19 May 2012

Available online 13 June 2012

\section{Keywords:}

Crop model

CSM

DSSAT

Genetic algorithm

Hyperspectral

LAI

Model inversion

Nitrogen

Optimization

PEST

PROSAIL

Simulation

Wheat

Yield

\begin{abstract}
A B S T R A C T
Remote sensing technology can rapidly provide spatial information on crop growth status, which ideally could be used to invert radiative transfer models or ecophysiological models for estimating a variety of crop biophysical properties. However, the outcome of the model inversion procedure will be influenced by the timing and availability of remote sensing data, the spectral resolution of the data, the types of models implemented, and the choice of parameters to adjust. Our objective was to investigate these issues by inverting linked radiative transfer and ecophysiological models to estimate leaf area index (LAI), canopy weight, plant nitrogen content, and yield for a durum wheat (Triticum durum) study conducted in central Arizona over the winter of 2010-2011. Observations of crop canopy spectral reflectance between 268 and $1095 \mathrm{~nm}$ were obtained weekly using a GER 1500 spectroradiometer. Other field measurements were regularly collected to describe plant growth characteristics and plant nitrogen content. Linkages were developed between the DSSAT Cropping System Model (CSM) and the PROSAIL radiative transfer model (CSM-PROSAIL) and between the DSSAT-CSM and an empirical model relating NDVI to LAI (CSM-Choudhury). The PEST parameter estimation algorithm was implemented to adjust the leaf area growth parameters of the CSM by minimizing error between measured and simulated NDVI or canopy spectral reflectance. A genetic algorithm was implemented to identify the optimum combination of remote sensing observations required to optimize simulations of LAI through model inversion. The relative root mean squared error (RRMSE) between measured and simulated LAI was $24.1 \%$ for the CSM-PROSAIL model, whereas the stand-alone PROSAIL and CSM models simulated LAI with RRMSEs of $40.7 \%$ and $27.8 \%$, respectively. Wheat yield was simulated with RRMSEs of $12.8 \%$ and $10.0 \%$ for the lone CSM model and the CSM-PROSAIL model, respectively. Optimized leaf area growth parameters for CSM-PROSAIL were different among cultivars $(p<0.05)$, while those for CSM-Choudhury were not. Only two observations, one at mid-vegetative growth and one at maximum vegetative growth, were required to optimize LAI simulations for CSM-PROSAIL, whereas CSM-Choudhury required four observations. Inverting CSM-PROSAIL using hyperspectral data offered several advantages as compared to the CSM-Choudhury inversion using a simple vegetation index, including better estimates of crop biophysical properties, different leaf area growth parameter estimates among cultivars $(p<0.05)$, and fewer required remote sensing observations for optimum LAI simulation.
\end{abstract}

Published by Elsevier Inc.

\section{Introduction}

Remote sensing instruments are routinely used to monitor agricultural fields from tractor-mounted, airborne, and satellite platforms (Davies, 2009; Xie et al., 2008). Typically, these instruments measure the amount of light reflected from the crop scene after incoming radiation has interacted with the crop canopy and underlying soil background. A remaining challenge for agricultural and remote sensing scientists is to understand how this information can be effectively

\footnotetext{
* Corresponding author. Tel.: + 1 5203166375; fax: + 15203166330 E-mail address: kelly.thorp@ars.usda.gov (K.R. Thorp).
}

utilized to characterize biophysical properties of the crop canopy, forecast crop yield, and guide agricultural resource management for water and nitrogen fertilizer. One approach is to use the remote sensing observations for inversion of physical or ecophysiological simulation models.

A numerical model for a given system is typically designed to convert system attributes to observable quantities. For example, the PROSAIL radiative transfer model uses plant canopy attributes and solar geometry to simulate canopy spectral and bidirectional reflectance at a given time (Jacquemoud et al., 2009). Model inversion utilizes an optimization algorithm to do the reverse, using the observed data to infer the system attributes. Several studies have used observed canopy spectral reflectance to invert the PROSAIL model and 
estimate crop biophysical properties, such as leaf chlorophyll content (Botha et al., 2007, 2010) and leaf water content (Yang \& Ling, 2004). Also, Goel and Strebel (1983) demonstrated the inversion of the Suits model to estimate leaf area index (LAI) based on infrared canopy reflectance. Although model inversion offers a reasonable way to estimate system attributes from remote sensing observations, the procedure is not without challenges and risks. One concern is that due to incomplete knowledge of system processes, simplifications in model design, and input parameter error, different configurations of a model may provide equally reasonable results, a condition known as equifinality (Luo et al., 2009). Such problems have been reported for inversions of many simulation models, including PROSAIL (Jacquemoud, 1993; Jacquemoud et al., 1995). To address this concern, Combal et al. (2003) showed that PROSAIL model inversions could be improved with adequate model constraint using known, prior information. In this study, we aim to provide such constraint using results from an ecophysiological model that simulates the interrelationship between crop growth processes and the environment.

The complementary nature of remote sensing and ecophysiological modeling has been known since their inception (Wiegand et al., 1979). Maas (1988) has demonstrated how satellite remote sensing data could be used to invert a sorghum (Sorghum bicolor (L.) Moench) growth model and greatly improve the simulated yield. However, remote sensing and ecophysiological modeling technologies have largely been developed independently from each other. For example, the Cropping Systems Model (CSM), as provided in the Decision Support System for Agrotechnology Transfer (DSSAT), is an ecophysiological model that simulates crop growth and development processes and the effects of soil water and nutrient status on crop yield (Jones et al., 2003). However, the model does not simulate any processes related to the interaction of radiation within the crop canopy. Likewise, although PROSAIL can simulate crop canopy spectral and bidirectional reflectance, the model does not simulate any processes related to crop, water, or nutrient dynamics. More recently, radiative transfer models have been explicitly linked to ecophysiological models through common state variables, particularly the LAI (Guerif \& Duke, 2000; Koetz et al., 2005; Prevot et al., 2003). This approach has resulted in more comprehensive models capable of simulating the temporal canopy spectral reflectance response as well as the underlying crop, water, and nutrient processes of the cropping system.

Establishing links between radiative transfer and ecophysiological models offer several advantages for model inversion applications that involve remote sensing observations. The radiative transfer model aids ecophysiological model parameterization and permits model inversion by providing a direct link to easily observable reflectance characteristics of the crop canopy. Simulation results from the ecophysiological model can then be used to constrain the input parameters of the radiative transfer model and permit estimation of crop yield and other biophysical variables that cannot be estimated with radiative transfer model inversion alone. The ecophysiological model also permits model inversion based on time series remote sensing observations, rather than static, point-in-time measurements.

In designing a model inversion strategy for linked radiative transfer and ecophysiological models, a plethora of procedural questions arise, including which model parameters to adjust, which parameters to constrain, which spectral wavelengths to use, and which time series remote sensing observations to incorporate. First, ecophysiological models are typically complex with many input parameters available for adjustment. We hypothesize that the model inversion scheme should focus on adjusting parameters that directly affect the crop states shared between the ecophysiological and radiative transfer model. Second, increasing availability of hyperspectral instrumentation permits collection of narrow-band spectral reflectance data (Green et al., 1998; Rodriguez et al., 2011). However, it is unclear whether the additional spectral information offers an advantage for model inversion problems as compared to common broad-band vegetation indices, such as the normalized difference vegetation index (NDVI). Finally, the timing and availability of remote sensing observations will affect the performance of model inversion procedures and the accuracy of the estimated crop biophysical properties. Few studies have investigated these aspects of model inversion based on canopy spectral reflectance data.

The overall objective of this work was to investigate the use of model inversion procedures to estimate crop biophysical properties through linked ecophysiological and radiative transfer models. We focus on estimation of LAI, canopy weight, plant nitrogen content, and yield for a durum wheat (Triticum durum) crop in central Arizona. Estimates of these crop properties with the inverted, linked models are compared with those from inversions of the stand-alone radiative transfer models (for LAI only) and from simulations with the standalone ecophysiological model (DSSAT-CSM). Secondarily, we assess the added value of hyperspectral information for model inversion by testing two radiative transfer models: one simulates full spectrum reflectance (PROSAIL) and another is based on NDVI (Choudhury et al., 1994). Finally, we investigate the issue of remote sensing data availability by implementing a genetic algorithm to find the set of remote sensing observations that optimally estimates LAI using our model inversion approach.

\section{Materials and methods}

\subsection{Field experiment}

A wheat experiment was conducted at the University of Arizona's Maricopa Agricultural Center (MAC) near Maricopa, Arizona $\left(33.067547^{\circ} \mathrm{N}, 111.97146^{\circ} \mathrm{W}\right)$ over the winter of $2010-2011$. A split plot design with four replications of six wheat cultivars as main treatments and five nitrogen fertilizer applications rates as sub-treatments was used for the experiment. Wheat cultivars included Duraking, Topper, Kronos, Havasu, Orita, and Ocotillo. Wheat was planted on December 15, 2010 with a row spacing of $19.05 \mathrm{~cm}$. Urea nitrogen fertilizer was applied at the rates given in Table 1 using a portable fertilizer spreader. A Sudan grass cover crop was grown in the summer of 2010 to remove excess nitrate from the soil. The entire experimental area was flood irrigated to avoid water deficits. The total depth of irrigation water was $951 \mathrm{~mm}$, applied in 9 irrigation events from December 15, 2010 to May 4, 2011. Irrigation water provided approximately $5 \mathrm{~kg} \mathrm{ha}^{-1}$ of nitrate at each irrigation event. Precipitation amounted to $29.3 \mathrm{~mm}$ over the growing season. The soil texture at the site was predominantly sandy loam and sandy clay loam, as determined by textural analysis of soil samples collected after planting.

\subsection{Biomass and yield measurements}

Wheat plants were destructively sampled from the 120 experimental plots on four dates: January 18, February 24, March 22, and April 7 of 2011 (Table 2). Plants in two $0.5 \mathrm{~m}$ row lengths within each plot were cut at the soil surface and immediately placed in coolers. Within $24 \mathrm{~h}$, wheat plants were dissected into component plant parts, including leaves, stems, and boots. The total leaf area of each sample was measured using an area meter (model 3100,

Table 1

Nitrogen fertilizer application schedule $\left(\mathrm{kg} \mathrm{ha}^{-1}\right)$ for the five nitrogen rate treatments in the 2010-2011 wheat experiment.

\begin{tabular}{llrrrr}
\hline Date & N1 & N2 & N3 & N4 & N5 \\
\hline Jan 18 & 0 & 18 & 36 & 65 & 94 \\
Feb 9 & 0 & 13 & 24 & 36 & 48 \\
Mar 25 & 0 & 24 & 36 & 48 & 71 \\
Apr 11 & 0 & 24 & 36 & 48 & 71 \\
Total & 0 & 79 & 132 & 197 & 284 \\
\hline
\end{tabular}




\section{Table 2}

Means of plant measurements, including leaf area index (LAI), canopy weight (biomass; $\mathrm{Mg} \mathrm{ha}^{-1}$ ), and plant nitrogen ( $\left.\mathrm{N}, \%\right)$, among wheat cultivars for the five nitrogen rate treatments on four sampling dates. Mean grain yield $\left(\mathrm{Mg} \mathrm{ha}^{-1}\right)$ among wheat cultivars is also given for each nitrogen rate treatment.

\begin{tabular}{llllllr}
\hline & Date & N1 & N2 & N3 & N4 & N5 \\
\hline LAI & Jan 18 & 0.06 & 0.08 & 0.07 & 0.05 & 0.06 \\
LAI & Feb 24 & 0.33 & 0.67 & 0.91 & 1.15 & 1.39 \\
LAI & Mar 22 & 1.07 & 1.83 & 2.25 & 1.91 & 3.64 \\
LAI & Apr 7 & 1.21 & 2.01 & 2.48 & 3.08 & 3.83 \\
Biomass & Jan 18 & 0.12 & 0.13 & 0.12 & 0.12 & 0.12 \\
Biomass & Feb 24 & 0.64 & 1.03 & 1.15 & 1.43 & 1.78 \\
Biomass & Mar 22 & 2.13 & 3.61 & 4.77 & 5.46 & 6.03 \\
Biomass & Apr 7 & 3.48 & 6.27 & 8.19 & 8.97 & 10.14 \\
Plant N & Jan 18 & 3.16 & 3.25 & 3.33 & 3.25 & 3.16 \\
Plant N & Feb 24 & 1.95 & 2.14 & 2.39 & 2.71 & 3.16 \\
Plant N & Mar 22 & 1.12 & 1.08 & 1.29 & 1.36 & 1.39 \\
Plant N & Apr 7 & 0.56 & 0.70 & 0.78 & 0.84 & 1.12 \\
Yield & Jun 2 & 1.69 & 3.60 & 4.91 & 6.54 & 7.02 \\
\hline
\end{tabular}

Li-Cor, Lincoln, Nebraska), and LAI was calculated from these measurements. Plant biomass was oven dried to obtain the dry weight of each sample. The dried biomass was then finely ground, and samples were prepared for analysis of nitrogen content. A Carlo Erba elemental analyzer (model NA1500 N/C, Carlo Erba Instruments, Milan, Italy) was used to obtain the percent nitrogen content of each plant sample. The mature crop was harvested with a plot combine on June 2, 2011. A sample of grain was oven dried to estimate dry grain weight for each plot.

\subsection{Radiometric measurements}

Leaf area index was also measured on a weekly basis using a Li-Cor Plant Canopy Analyzer (model LAI-2000, Li-Cor, Lincoln, Nebraska). Since the instrument requires diffuse conditions for accurate readings, the measurements were typically collected either in the early morning or late afternoon hours and an umbrella was used to block the direct solar beam. Five below-canopy readings were taken between two above-canopy readings.

Ground-based radiometric measurements were collected weekly over each experimental plot using a portable field spectroradiometer (GER 1500, Spectra Vista Corp., Poughkeepsie, New York). Additional measurements were collected over a bare soil area within the experimental field. Information was collected in 512 narrow wavebands from 268 to $1095 \mathrm{~nm}$ with bandwidth ranging from 1.5 to $2.1 \mathrm{~nm}$. The instrument was equipped with an $18^{\circ}$ field-of-view fiber optic. A wand constructed from PVC tubing was used to position the fiber optic at a nadir view angle approximately $1.8 \mathrm{~m}$ above the soil surface. Spectral measurements typically occurred in the morning around the time of a $57^{\circ}$ solar zenith angle, which insured consistent canopy bidirectional reflectance effects over the course of the entire growing season. Frequent radiometric observations of a calibrated, $0.6 \mathrm{~m}^{2}, 99 \%$ Spectralon panel (Labsphere, Inc., North Sutton, New Hampshire) were used to characterize solar irradiance throughout the data collection period. Canopy reflectance factors in each waveband were computed as the ratio of the canopy radiance over the corresponding time-interpolated value for solar irradiance. Reflectance factors from three radiometric measurements over each experimental plot were averaged to estimate the canopy spectral reflectance of the plot on each measurement date.

\subsection{Radiative transfer models}

Two radiative transfer models, including the method of Choudhury et al. (1994) and the PROSAIL model (Jacquemoud et al., 2009), were used to link the canopy spectral reflectance data to DSSAT-CSM simulations of wheat growth.

\subsubsection{Choudhury method}

The method of Choudhury et al. (1994) is based on the wellknown normalized difference vegetation index (NDVI). Fractional vegetation cover $(f)$ is computed from NDVI using:

$f=1-\left\{\frac{N D V I_{\max }-N D V I}{N D V I_{\max }-N D V I_{\min }}\right\}^{1 / \zeta}$

where NDVI measurements are rescaled according to the bare soil index $\left(\mathrm{NDVI}_{\text {min }}\right)$ and the full vegetation cover index $\left(\mathrm{NDVI}_{\max }\right)$. The parameter $\zeta$ is a function of canopy leaf angle distribution with values near 1.4 for erectophile canopies and near 0.8 for planophile canopies. Leaf area index (LAI) is computed from $(f)$ according to:

$L A I=\frac{\ln (1-f)}{-\beta}$

where $\beta$ is a second function of leaf angle distribution that ranges from 0.42 to 0.91 . To parameterize the Choudhury model, $\zeta$ and $\beta$ were adjusted to minimize error between model-estimated and field-measured LAI. The resulting parameter values, 1.78 for $\zeta$ and 0.66 for $\beta$, were used for all subsequent Choudhury model calculations in this study.

\subsubsection{PROSAIL}

The PROSAIL canopy reflectance model was developed by linking the PROSPECT leaf optical properties model and the SAIL canopy bidirectional reflectance model (Jacquemoud et al., 2009). PROSAIL uses 14 input parameters to define leaf pigment content, leaf water content, canopy architecture, soil background reflectance, hot spot size, solar diffusivity, and solar geometry. Leaf pigment content is defined by the chlorophyll $a$ and $b$ content $\left(C_{a b} ; \mu \mathrm{g} \mathrm{cm}{ }^{-2}\right)$, carotenoid content $\left(C_{c r} ; \mu \mathrm{g} \mathrm{cm}{ }^{-2}\right)$, and brown pigment content $\left(C_{b p}\right)$. Leaf water content is defined as the equivalent water thickness $\left(C_{w} ; \mathrm{cm}\right)$. Canopy architecture is defined using four parameters, including the leaf dry matter content $\left(C_{m} ; \mathrm{g} \mathrm{cm}^{-2}\right)$, leaf structural coefficient $(N)$, leaf area index (LAI), and average leaf inclination angle ( $\theta_{l}$; degrees). Solar geometry is characterized by the solar zenith, observer zenith, and solar azimuth angles. Based on these inputs, the model calculates canopy bidirectional reflectance from 400 to $2500 \mathrm{~nm}$ in $1 \mathrm{~nm}$ increments.

For stand-alone PROSAIL inversion and for linkage to the ecophysiological model, we focused primarily on the $C_{a b}$ and LAI parameters. All other parameters were either held constant or specified from measurements (Fig. 1). The $C_{c r}$ and $C_{b p}$ parameters were fixed at $20.0 \mu \mathrm{g} \mathrm{cm}^{-2}$ and 0.0 , respectively. Equivalent water thickness was fixed at $0.02 \mathrm{~cm}$ based on the work of Botha et al. (2010) for wheat in Canada. Leaf dry matter content was fixed at $0.006 \mathrm{~g} \mathrm{~cm}^{-2}$ based on our biomass measurements. The structural parameter, $N$, and the average leaf inclination angle were manually adjusted to improved PROSAIL inversion results for LAI. Resulting parameter values, 1.35 for $N$ and $59^{\circ}$ for $\theta_{l}$, were within the ranges given by Botha et al. (2010) and Jacquemoud (1993) and were used for all subsequent PROSAIL simulations in this study. The soil background reflectance parameter was determined from bare soil reflectance observations on each measurement date. The solar diffusivity parameter was fixed at $15 \%$ based on observations of a shaded versus sunlit Spectralon panel during the field study. The hot spot size parameter was fixed at 1.0. By implementing the solar position algorithm of Reda and Andreas (2004), solar zenith angles were calculated from the timestamp of each radiometric observation in the field. Observer zenith and solar azimuth angles were both fixed at $0^{\circ}$.

\subsection{Ecophysiological model}

The DSSAT Cropping System Model (CSM; ver. 4.5.1.005) is an ecophysiological model that programmatically synthesizes current 


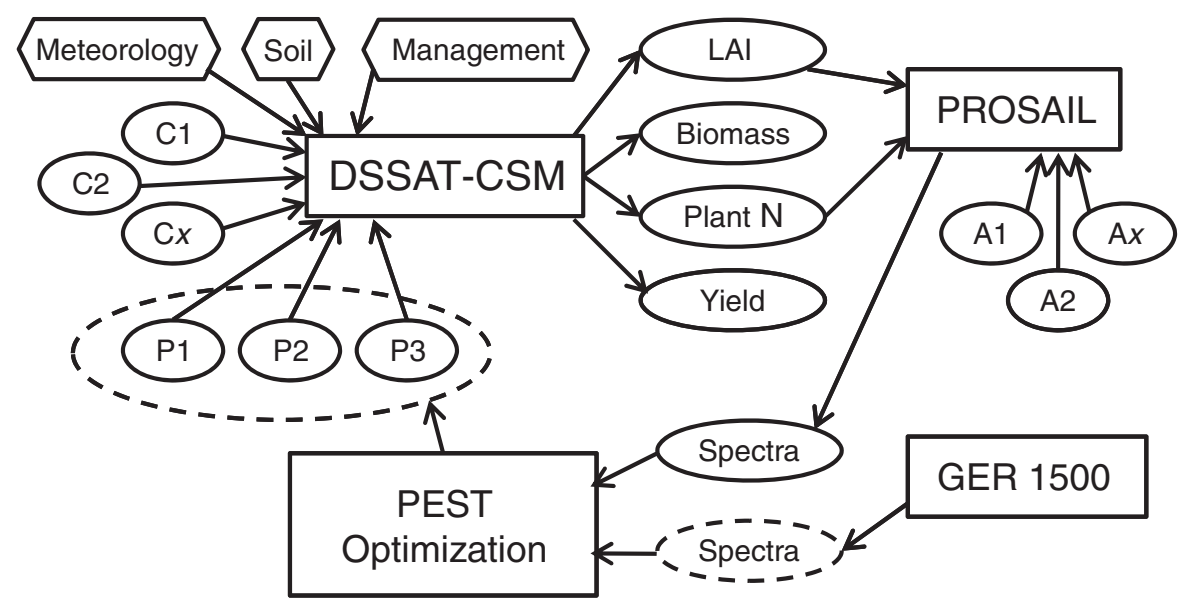

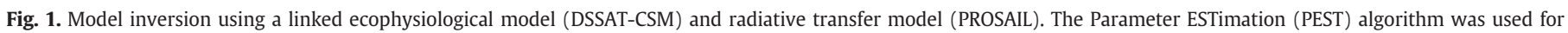

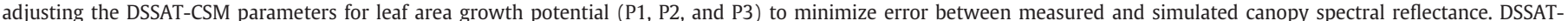
CSM simulated LAI and plant nitrogen $(\mathrm{N})$ provided information to PROSAIL for spectral reflectance simulations.

knowledge of cropping system processes (Jones et al., 2003). The model utilizes mass balance principles to simulate the carbon, nitrogen, and hydrologic processes and transformations that occur within a cropping system. Simulations of crop development and growth for over 25 crop species are possible, but we implemented only the CSM-CROPSIM-CERES-Wheat model to simulate wheat growth and development for the experimental conditions of our field study. The CSM calculates cropping system processes within a homogeneous area on a daily time step, and certain subprocesses are computed hourly. Crop development proceeds through a series of growth stages based on heat unit accumulation from planting to harvest. Photosynthesis is computed using a radiation use efficiency approach in CSMCROPSIM-CERES-Wheat. Assimilated carbon is partitioned to various plant parts, including leaves, stems, roots, and grain. Simulated plant growth responds to variation in management practices, cultivar selection, soil properties, and meteorological conditions (Fig. 1). Management inputs required for model execution include plant population, row spacing, seed depth, planting dates, fertilizer application amounts and dates, and irrigation application amounts and dates. Cultivar parameters define day length sensitivity, heat units needed to progress through growth stages, and growth potentials for specific plant parts. Soils are defined by their water retention and conductivity characteristics, bulk density, $\mathrm{pH}$, and initial conditions for water, inorganic nitrogen, and organic carbon. We implemented the FAO56 option for evapotranspiration calculations, which requires daily inputs for minimum and maximum temperature, solar radiation, wind speed, and dew point temperature. The model simulates plant stress effects from deficit and excess soil water conditions and from deficit soil nitrogen conditions, which feedback on the daily plant growth simulation.

All crop management inputs for crop planting, irrigation, and nitrogen fertilizer applications were specified as performed during the field investigation. Initial soil water content was set near the lower limit due to the arid conditions of our field site, and initial soil nitrogen contents were low due to cover crop usage in the summer preceding the field experiment. Soil water retention and hydraulic parameters were specified based on a textural analysis of soil samples at the site. The Rosetta pedotransfer functions (Schaap et al., 2001) were used to calculate the required soil input parameters from textural information. Meteorological data were obtained from an Arizona Meteorological Network (AZMET; http://ag.arizona.edu/ azmet/) station approximately $100 \mathrm{~m}$ from the field site. For baseline simulations with the CSM, several cultivar parameters were manually adjusted to improve simulated crop growth and development as compared to field observations. These parameters were set based on the average condition of all six cultivars in the field study. The vernalization (P1V) and day length sensitivity (P1D) parameters were adjusted to values of 30 and 35, respectively, to improve simulations of anthesis date as compared to observed. The interval between successive leaf tip appearances (PHINT) parameter was adjusted to $100{ }^{\circ} \mathrm{C} \mathrm{d}$ to improve simulations of leaf number as compared to observed. Also, the kernel number (G1) and kernel size (G2) parameters were adjusted to 26 kernels and $26.5 \mathrm{mg}$, respectively, to minimize error between measured and simulated yield for the highest (nonstressed) fertilizer rate treatment.

\subsection{Model linkages}

As described by Thorp et al. (2010), the CSM-CROPSIM-CERESWheat model calculates LAI as an area-based output variable after first calculating crop states at the scale of individual plants. Thus, the linkage of the CSM to each radiative transfer model was established immediately after calculating LAI from total plant leaf area. The Choudhury et al. (1994) model was implemented by programming CSM to back-calculate NDVI from its LAI state variable using Eqs. (1) and (2). This permitted the CSM to calculate NDVI as an output on each timestep (CSM-Choudhury). Both the CSM and PROSAIL have been developed in the Fortran programming language, which simplified their linkage. The Fortran code for CSM and PROSAIL were merged and compiled as a single executable file (CSM-PROSAIL). The link from CSM to PROSAIL was established by using CSM's LAI and leaf nitrogen state variables to specify the LAI and $C_{a b}$ parameters in PROSAIL (Fig. 1). Based on data given in Evans (1983), the CSM leaf nitrogen state variable $\left(\mathrm{g} \mathrm{cm}^{-2}\right)$ was converted to $C_{a b}\left(\mu \mathrm{g} \mathrm{cm}{ }^{-2}\right)$ using a multiplication factor of 233,000 . This permitted the CSM to simulate canopy bidirectional reflectance between 400 and $2500 \mathrm{~nm}$ on a daily basis given that other required PROSAIL model parameters were also specified.

\subsection{PEST algorithm}

Model inversion procedures were conducted using the Parameter ESTimation (PEST) software developed by Doherty (2005). PEST was used to adjust CSM's leaf area growth potentials to minimize error between measured and simulated canopy spectral reflectance for the CSM-PROSAIL model (Fig. 1). Model inversion procedures were similar for the CSM-Choudhury model, with the exceptions that the Choudhury et al. (1994) model replaced PROSAIL and that PEST minimized error between measured and simulated NDVI. Three cultivar parameters govern the leaf area growth potential in CSM-CROPSIM- 
CERES-Wheat, including the area of the standard first leaf (LA1S, $\mathrm{cm}^{2}$ ), the vegetative phase leaf area adjustment factor (LAFV), and the reproductive phase leaf area adjustment factor (LAFR). We set PEST to optimize LA1S and LAFV, while LAFR was tied to LAFV such that their resulting optimized parameter values were identical. LA1S was allowed to vary between 0.5 and $2.5 \mathrm{~cm}^{2}$. LAFV was allowed to vary from 0.01 to 3.00 . Limits for these parameters were chosen using a sensitivity analysis to assess their impact on simulated LAI. We also attempted to adjust other CSM parameters, such as the plant population, the potential specific leaf weight, the growth stage durations, and the soil fertility factor. However, preliminary PEST results demonstrated that the leaf area growth potentials were the most effective CSM parameters for this optimization problem. Therefore, we finally focused on optimizing only the three parameters that define the leaf area growth: LA1S, LAFV, and LAFR.

\subsection{Genetic algorithm}

Inversion of the CSM-Choudhury and CSM-PROSAIL models and accuracy of the estimated crop biophysical properties were expected to be heavily influenced by the timing and availability of remote sensing observations. Field outings with the GER 1500 spectroradiometer resulted in 16 observations of canopy spectral reflectance in each plot, which were collected on a near weekly basis. Observations were available on the following days after planting: $30,34,42,48$, $54,61,69,71,77,83,91,97,105,113,119$, and 125 . To assess the impact of observation timing and availability, a genetic algorithm was implemented to find the set of remote sensing observations that optimally estimated LAI through inversion of CSM-Choudhury and CSM-PROSAIL. We focused on selecting the observations that optimized LAI, because it was likely the most fundamental state variable affected by adjusting the leaf area growth parameters during model inversion.

To set up the genetic algorithm, a chromosome with 16 1-bit genes was established, one gene for each remote sensing observation date. Each bit indicated whether the remote sensing observation from its respective date should or should not be included in the PEST optimization (Fig. 1). A two-point crossover method was used with a crossover rate of 0.90 , and a bit flip mutation method was used with a mutation rate of 0.06 . The population size was 47 . For further constraint, the algorithm was seeded with the optimum results of model inversions based on all possible combinations of one, two, and three remote sensing observations. The algorithm was allowed to run for 100 generations, although the optimum set of remote sensing observations was usually found within 5 generations. Results for CSMChoudhury and CSM-PROSAIL are reported for the set of remote sensing observations that achieved the optimum LAI simulation results.

To summarize, we used the genetic algorithm to select which remote sensing observations to include in the model inversion procedure (Fig. 1). Actual adjustment of the model parameters to minimize error between measured and simulated NDVI or canopy spectral reflectance was accomplished with the PEST optimization algorithm, described in the previous section.

\subsection{Analysis}

The Choudhury et al. (1994) and PROSAIL radiative transfer models provided a link between CSM-simulated LAI and canopy spectral reflectance, such that we could use model inversion to optimize leaf area growth simulations based on remote sensing observations of wheat canopy spectral reflectance. We assessed the value of this approach for estimating key crop biophysical properties, including LAI, canopy weight, plant nitrogen content, and crop yield (Fig. 1). We also compared results between the linked models and their stand-alone components. The following assessments were made using data for each treatment in the field study:
- Choudhury alone - The $\zeta$ and $\beta$ parameters in the Choudhury et al. (1994) model were adjusted to minimize error between modelestimated and field-observed LAI. The NDVI was calculated by averaging GER 1500 canopy spectral reflectance observations within the Landsat TM wavebands for red (630 to $690 \mathrm{~nm}$ ) and near-infrared (760 to $900 \mathrm{~nm}$ ) radiation. This approach only provided an estimate of LAI.

- PROSAIL alone - PEST was implemented to invert the PROSAIL model by adjusting the LAI and $C_{a b}$ parameters to minimize error between simulated and observed canopy spectral reflectance from 400 to $900 \mathrm{~nm}$. This approach provided an estimate of LAI and $C_{a b}$.

- CSM alone - Stand-alone CSM simulations provided baseline estimates for LAI, canopy weight, plant nitrogen content, and wheat yield without any PEST optimization. Only the manual parameter adjustments described previously were incorporated in these simulations. Leaf area growth potentials were left at default values, and the model was not parameterized to simulate any cultivar differences. Only fertilizer management differences were simulated.

- CSM-Choudhury - PEST was implemented to invert the CSMChoudhury model by adjusting CSM's leaf area growth potentials to minimize error between measured and simulated NDVI through the Choudhury et al. (1994) model linkage. Observed NDVI was calculated by averaging the GER 1500 canopy spectral reflectance observations within the Landsat TM wavebands for red (630 to $690 \mathrm{~nm}$ ) and near-infrared (760 to $900 \mathrm{~nm}$ ) radiation. The genetic algorithm was implemented to find the set of remote sensing observations that optimally estimated LAI through model inversion.

- CSM-PROSAIL - PEST was implemented to invert the CSM-PROSAIL model by adjusting CSM's leaf area growth potentials to minimize error between measured and simulated canopy spectral reflectance observations from 400 to $900 \mathrm{~nm}$ through the PROSAIL linkage (Fig. 1). The genetic algorithm was implemented to find the set of remote sensing observations that optimally estimated LAI through model inversion.

Results for LAI were evaluated by calculating the relative root mean squared error (RRMSE) between measured and simulated LAI on dates with LAI-2000 Plant Canopy Analyzer measurements. For canopy weight and plant nitrogen content, the RRMSE between measured and simulated values was calculated on biomass collection dates. The RRMSE between measured and simulated yield was also computed. The R statistical software (www.r-project.org) was used to conduct an analysis of variance and Tukey's multiple comparisons test on the optimized leaf area growth parameters resulting from inversion of CSM-Choudhury and CSM-PROSAIL.

\section{Results and discussion}

\subsection{LAI observations}

Since LAI was a key variable in this study, we measured it using two field methods, one based on readings from the Li-Cor LAI-2000 Plant Canopy Analyzer and the other based on processing of biomass samples. A primary advantage of the Li-Cor LAI meter was its relatively quick and easy measurement protocol, whereas processing of biomass samples was quite labor-intensive and time-consuming. We were able to estimate LAI on a weekly basis with the Li-Cor LAI meter, whereas biomass samples were collected and processed only four times throughout the growing season. Since the Li-Cor LAI data were more plentiful, we used these data to evaluate the model simulations. Fig. 2 compares LAI observations from the Li-Cor meter and from biomass sampling for the four days when estimates of LAI from biomass samples were available. The RMSE between LAI observations for these two field methods was 0.52 . We concluded that the Li-Cor LAI2000 Plant Canopy Analyzer could reasonably estimate LAI and could be used for further evaluation of model simulations. 


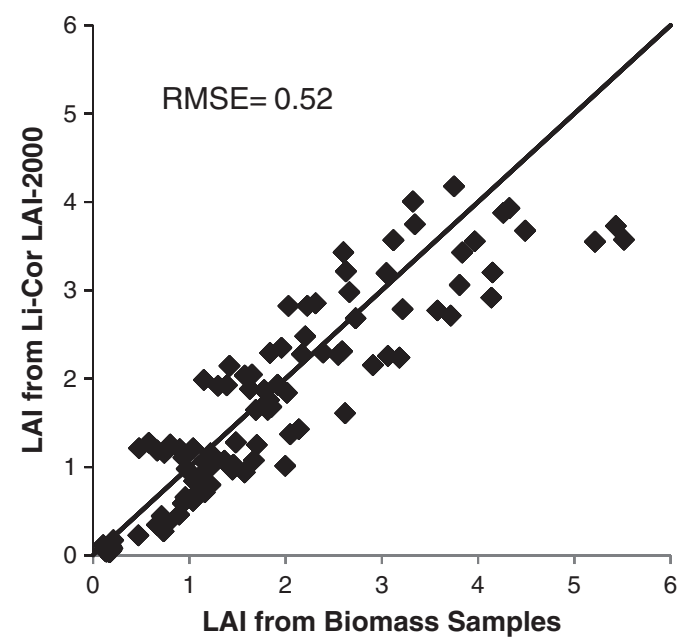

Fig. 2. Leaf area index (LAI) measured with the Li-Cor LAI-2000 Plant Canopy Analyzer versus the LAI estimated through processing of wheat biomass.

\subsection{Estimating $L A I$}

Relationships between measured and simulated LAI for each of the five modeling scenarios is given in Fig. 3. The stand-alone Choudhury model provided reasonable LAI estimates over the entire growing season (Fig. 3a) with a 29.4\% RRMSE between measured and modeled LAI (Table 3). Relative to the other modeling scenarios, the Choudhury et al. (1994) model performed well, although its usefulness is limited only to LAI estimation. The stand-alone PROSAIL model inversion performed relatively poorly and had a tendency to overestimate LAI in the early season $(\mathrm{LAI}<2)$ and underestimate $\mathrm{LAI}$ in the mid to late season (LAI > 2) (Fig. 3b). As corroborated by Botha et al. (2010), the overestimation of LAI in the early season may be related to PROSAIL's assumption of canopy homogeneity. The RRMSE between measured and modeled LAI was $40.7 \%$ for PROSAIL alone (Table 3). Simulations
Table 3

Relative root mean squared error (\%) between measured and modeled leaf area index (LAI), canopy weight (biomass), plant nitrogen (N), and wheat yield.

\begin{tabular}{llllll}
\hline & $\begin{array}{l}\text { Choudhury } \\
\text { alone }\end{array}$ & $\begin{array}{l}\text { PROSAIL } \\
\text { alone }\end{array}$ & $\begin{array}{l}\text { CSM } \\
\text { alone }\end{array}$ & $\begin{array}{l}\text { CSM- } \\
\text { Choudhury }\end{array}$ & $\begin{array}{l}\text { CSM- } \\
\text { PROSAIL }\end{array}$ \\
\hline LAI & 29.4 & 40.7 & 27.8 & 24.8 & 24.1 \\
Biomass & - & - & 18.6 & 13.4 & 14.4 \\
Plant N & - & - & 50.7 & 38.1 & 36.8 \\
Yield & - & - & 12.8 & 12.4 & 10.0 \\
\hline
\end{tabular}

of LAI with the stand-alone CSM model were reasonable with a RRMSE of $27.8 \%$ (Table 3 ). However, the model tended to underestimate LAI observations between 1.5 and 2.5 (Fig. 3c). This issue was remediated using remote sensing data to adjust the leaf area growth potentials through the radiative transfer model linkages (Fig. 3d and e).

Simulations of LAI with the inverted CSM-Choudhury model were good with a RRMSE of $24.8 \%$ (Table 3 ). Similar results were obtained with the inverted CSM-PROSAIL model, which estimated LAI with a RRMSE of $24.1 \%$. Scatter plots of measured and simulated LAI from both the inverted CSM-Choudhury model and the inverted CSMPROSAIL model fit well to the one-to-one line (Fig. 3d and e). Notably, the inversion of CSM-PROSAIL estimated LAI better than either CSM or PROSAIL alone. Likewise, the inversion of CSM-Choudhury estimated LAI better than either CSM or the Choudhury model alone. This demonstrated the usefulness of the linkages between the radiative transfer and ecophysiological models. The temporal LAI simulation from CSM provided constraint to the PROSAIL model that was not available for inversions of PROSAIL alone. Likewise, PROSAIL provided the physical model necessary for adjusting CSM's leaf area growth parameters based on canopy spectral reflectance information. Together, the models were able to estimate LAI with greater accuracy than either model alone.

\subsection{Estimating canopy weight}

Canopy weight was estimated with RRMSEs of $18.6 \%, 13.4 \%$, and $14.4 \%$ for the stand-alone CSM model, the CSM-Choudhury inversion,
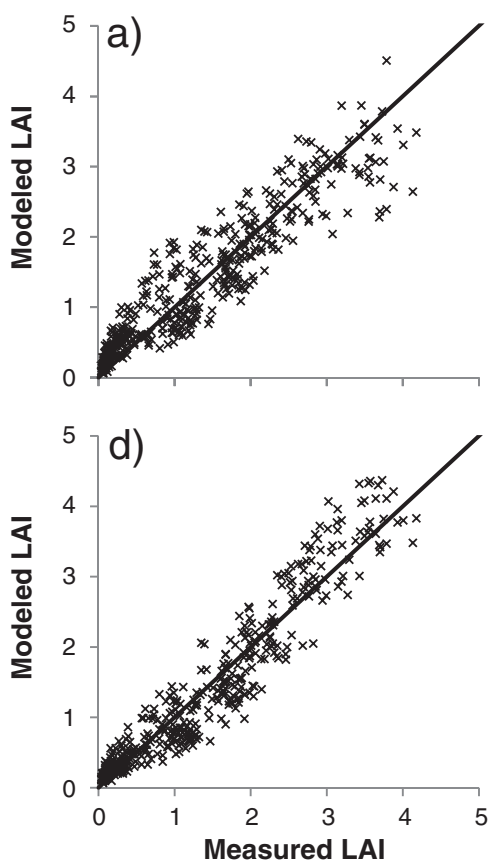
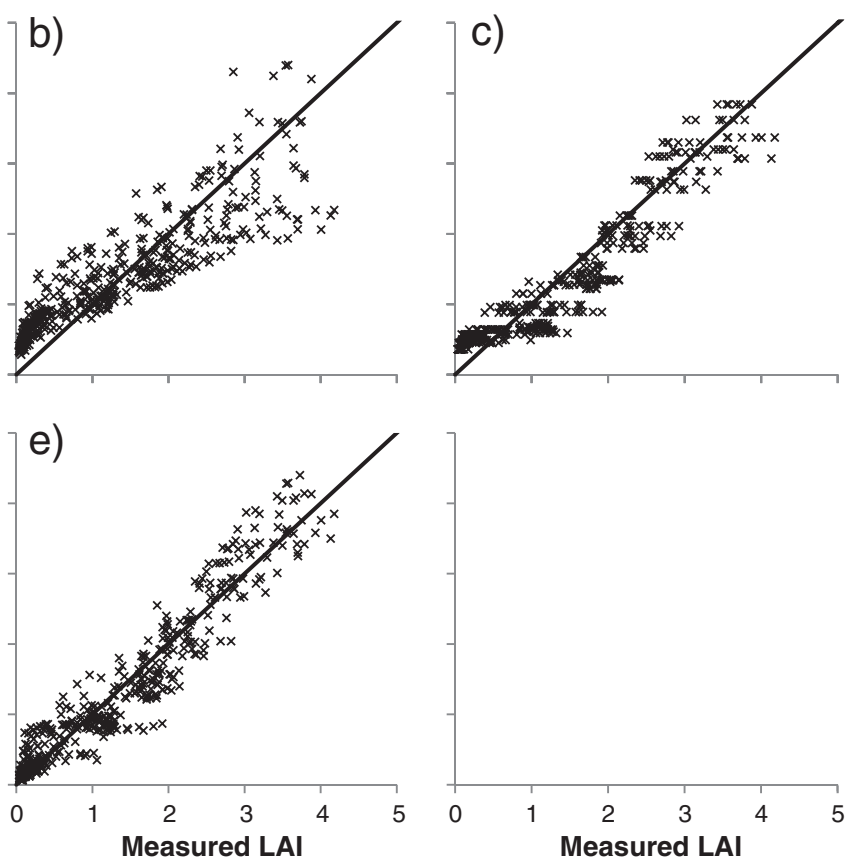

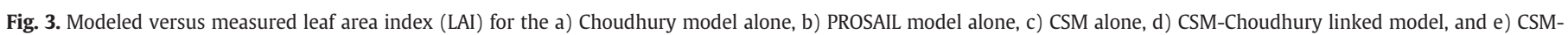
PROSAIL linked model. 

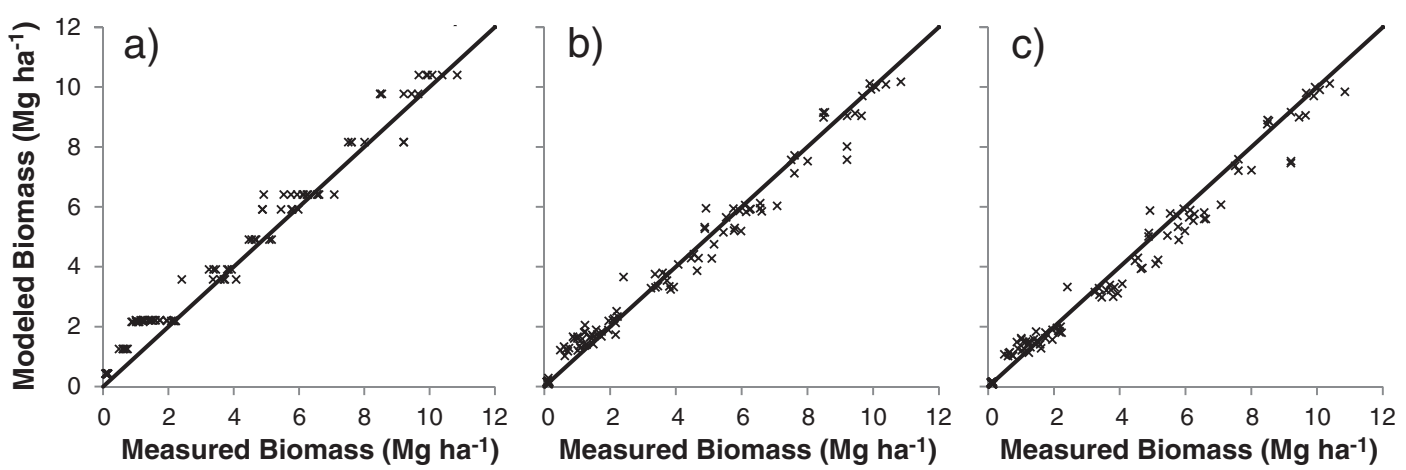

Fig. 4. Modeled versus measured wheat canopy weight (above ground biomass) for the a) CSM alone, b) CSM-Choudhury linked model, and c) CSM-PROSAIL linked model.

and the CSM-PROSAIL inversion, respectively (Table 3). Again, inverting the linked radiative transfer and ecophysiological models provided better estimates of canopy weight than simulations with CSM alone. The stand-alone CSM model used identical cultivar parameters to simulate all the treatments in the study, as demonstrated by the lack of variability in modeled results (Fig. 4a). By using remote sensing data to adjust the leaf area growth parameters for each unique treatment, we were able to account for cultivar differences that we did not simulate with CSM alone (Fig. 4b and c). The model inversion procedure may have also compensated for error in the specification of applied fertilizer rates for each nitrogen treatment. Use of remote sensing observations to adjust CSM's leaf growth parameters led to improved simulations of LAI (Fig. 3), and this improvement subsequently led to better estimates of canopy weight (Fig. 4) even though canopy weight was not explicitly used to constrain the radiative transfer model (Fig. 1). This further highlights an advantage of linking DSSAT-CSM with the radiative transfer models.

\subsection{Estimating plant nitrogen content}

Plant nitrogen content was simulated with RRMSEs of 50.7\%, 38.1\%, and $36.8 \%$ for the stand-alone CSM model, the CSM-Choudhury inversion, and the CSM-PROSAIL inversion, respectively (Table 3). Simulations of plant nitrogen content with the stand-alone CSM model were quite poor (Fig. 5), especially in the early growing season when observed plant nitrogen contents were greater than $2 \%$. Simulations of plant nitrogen content tended to reach a minimum threshold in the early season, which may be attributable to the tendency of the stand-alone CSM model to overestimate canopy weight at values less than $2 \mathrm{Mg} \mathrm{ha}^{-1}$ (Fig. 4a). Since plant nitrogen content is the ratio of plant nitrogen mass over canopy weight, overestimation of canopy weight at a given level of nitrogen uptake resulted in a minimization of plant nitrogen content. By using remote sensing data to adjust the simulations of LAI, improvements in the canopy weight simulations also improved the model's ability to simulation plant nitrogen content (Fig. 5b and c).

The coefficient of determination $\left(r^{2}\right)$ between the leaf-level chlorophyll content $\left(C_{a b}\right)$ from stand-alone PROSAIL model inversion and field-measured plant-level nitrogen content was 0.07 (not shown). To assess the reason for this poor relationship, we compared the $C_{a b}$ from PROSAIL model inversion with the $C_{a b}$ calculated from CSM-PROSAIL simulations of leaf nitrogen content using the relationship of Evans (1983). Results demonstrated an issue with the standalone PROSAIL model inversion procedure, similar to what has been reported elsewhere (Jacquemoud et al., 1995). Approximately 20\% of the PROSAIL model inversions resulted in an optimized $C_{a b}$ parameter value of $150 \mu \mathrm{g} \mathrm{cm}^{-2}$ (Fig. 6), which was the upper limit imposed for parameter optimization at outset. Increasing this upper limit would result in optimized $C_{a b}$ parameter values much higher than realistically anticipated. Decreasing the upper limit would likely cause a higher percentage of $C_{a b}$ parameter values to be optimized to the upper limit value, which reduces the value of inverting PROSAIL. When inverting the linked CSM-PROSAIL model, the $C_{a b}$ parameter was restrained by the physics of crop growth and nitrogen processes contained in the CSM. This resulted in $C_{a b}$ parameter values that were more stable and realistic around $59 \mu \mathrm{cm}^{-2}$ (Fig. 6).

\subsection{Estimating wheat yield}

A primary benefit of the linkage between radiative transfer and ecophysiological models is the ability to estimate (and ideally predict) crop yield based on remote sensing observations throughout the growing season. Our results showed that the radiative transfer model linkages did improve CSM simulations of wheat yield with RRMSEs of $12.8 \%, 12.4 \%$, and $10.0 \%$ for the stand-alone CSM model, the CSMChoudhury inversion, and the CSM-PROSAIL inversion, respectively (Table 3). Since the stand-alone CSM model was calibrated for yield simulations of the highest, non-stressed nitrogen treatment,
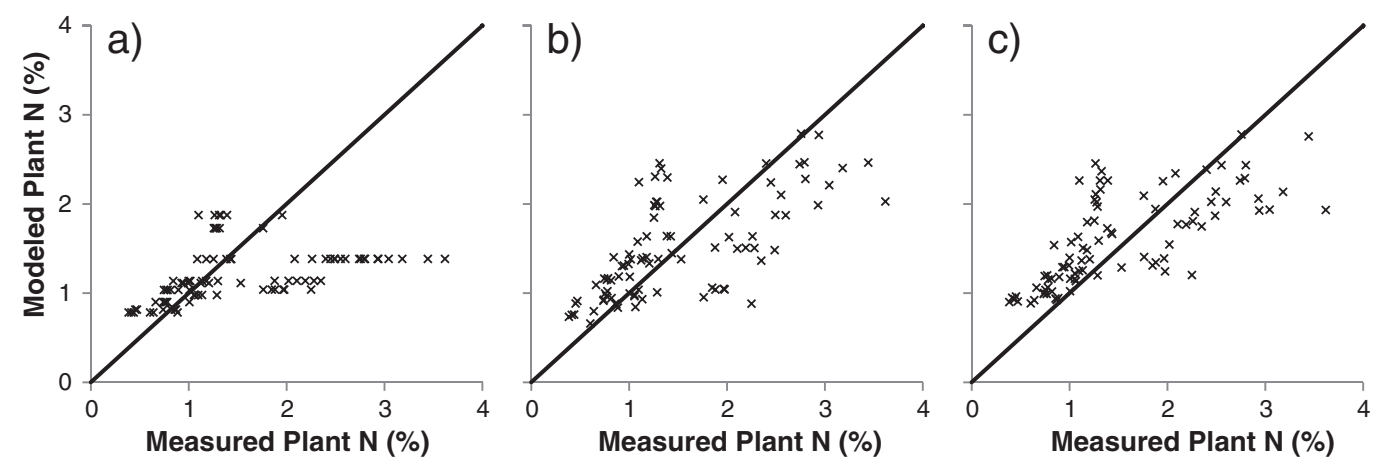

Fig. 5. Modeled versus measured plant nitrogen (N) content for the a) CSM alone, b) CSM-Choudhury linked model, and c) CSM-PROSAIL linked model. 


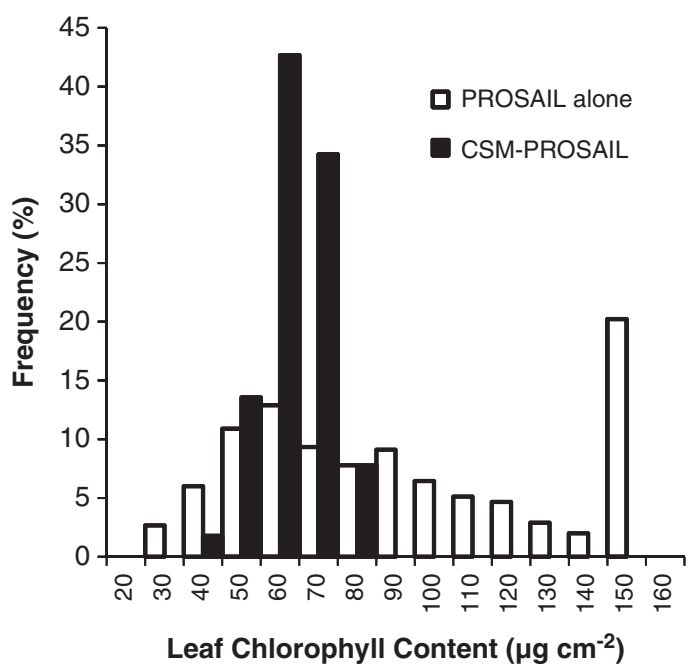

Fig. 6. Histogram of modeled chlorophyll $a$ and $b$ content for PROSAIL alone and for the CSM-PROSAIL linked model.

improvements in yield estimation using the radiative transfer model linkages were most apparent for the lower nitrogen rate treatments (Fig. 7). Improvements in the LAI simulation (Fig. 3), canopy weight simulation (Fig. 4) and the plant nitrogen simulation (Fig. 5) by adjusting leaf area growth parameters using remote sensing observations ultimately guided the model to improved simulations of wheat yield (Fig. 7).

\subsection{Estimating leaf area growth potential}

Further insights into the inversion of CSM-Choudhury and CSMPROSAIL were obtained by analyzing the leaf area growth parameters resulting from PEST optimization. A common problem of model inversion is aberrant optimized parameter values that tend to remain at the upper or lower boundaries imposed at the outset (Jacquemoud et al., 1995). This can result in non-normal histograms, similar to that obtained by inverting the stand-alone PROSAIL model to estimate $C_{a b}$ (Fig. 6). Out of 60 model inversion exercises for CSM-Choudhury and CSM-PROSAIL in this study ( 6 cultivars by 5 nitrogen rates for each model), 7 (12\%) resulted in an optimized leaf area growth parameter remaining at an upper or lower bound. All of these 7 resulted from the initial leaf size parameter (LA1S, $\mathrm{cm}^{2}$ ) remaining at the lower bound. Six of these occurred for CSM-PROSAIL model inversions at the lowest two nitrogen rates. The inversion procedure likely pushed the LA1S parameter down to account for growth reductions at the lower nitrogen rates.

Statistical analysis of the optimized parameter values demonstrated differences depending on the wheat cultivar and nitrogen rate. For CSM-Choudhury, there were differences in LAFV and LAFR among the
Table 4

Treatment means for the optimized leaf area growth parameters (LA1S, LAFV, and LAFR) from inversion of CSM-Choudhury. Letters indicate statistically significant groups at the 0.05 significance level. Results for LAFV and LAFR are identical, because we linked these parameters in the PEST optimization.

\begin{tabular}{llll}
\hline & LA1S & LAFV & LAFR \\
\hline Cultivar & & & \\
Duraking & $1.228 \mathrm{a}$ & $0.330 \mathrm{a}$ & $0.330 \mathrm{a}$ \\
Topper & $1.100 \mathrm{a}$ & $0.490 \mathrm{a}$ & $0.490 \mathrm{a}$ \\
Kronos & $1.289 \mathrm{a}$ & $0.368 \mathrm{a}$ & $0.368 \mathrm{a}$ \\
Havasu & $0.931 \mathrm{a}$ & $0.491 \mathrm{a}$ & $0.491 \mathrm{a}$ \\
Orita & $1.034 \mathrm{a}$ & $0.445 \mathrm{a}$ & $0.445 \mathrm{a}$ \\
Ocotillo & $1.142 \mathrm{a}$ & $0.496 \mathrm{a}$ & $0.496 \mathrm{a}$ \\
Nitrogen rate & & & \\
N1 & $1.318 \mathrm{a}$ & $0.249 \mathrm{a}$ & $0.249 \mathrm{a}$ \\
N2 & $1.067 \mathrm{a}$ & $0.374 \mathrm{ab}$ & $0.374 \mathrm{ab}$ \\
N3 & $1.281 \mathrm{a}$ & $0.435 \mathrm{abc}$ & $0.435 \mathrm{abc}$ \\
N4 & $0.995 \mathrm{a}$ & $0.534 \mathrm{bc}$ & $0.534 \mathrm{bc}$ \\
N5 & $0.942 \mathrm{a}$ & $0.593 \mathrm{c}$ & $0.593 \mathrm{c}$ \\
\hline
\end{tabular}

nitrogen rates $(p<0.05)$; however, there were no differences in LA1S (Table 4). No differences were found for any of the three parameters among the wheat cultivars. This means the inversion of CSMChoudhury mainly adjusted for error in the nitrogen simulation rather than accounting for any cultivar differences. Highlighting the added value of using the full canopy reflectance spectrum, the LAFV and LAFR parameters optimized for CSM-PROSAIL were statistically different among several of the wheat cultivars ( $p<0.05$, Table 5$)$. Differences in canopy spectral reflectance among the cultivars allowed the inversion procedure to find unique parameters for Duraking and Kronos cultivars as compared to Topper and Ocotillo. Given that we used the inversion procedure to adjust three cultivar parameters in the model, the finding of statistically different parameters based on crop cultivar is encouraging. However, no differences were found for the LA1S parameter with CSM-PROSAIL. Among the nitrogen rates, all three parameters showed differences with CSM-PROSAIL $(p<0.05)$. In particular, parameters for the lowest and highest nitrogen rate treatments were statistically different for all three parameters.

Further statistical analysis focused on the combined set of optimized parameters for CSM-Choudhury and CSM-PROSAIL. This showed statistically significant parameter values for LA1S, LAFV, and LAFR among the two model types ( $p<0.05$, Table 6$)$, and no statistical differences were found between cultivars and nitrogen rates in this case. LA1S defines the initial potential leaf size, whereas LAFV and LAFR define fractional increase in potential leaf size during the vegetative and reproductive growth phases, respectively. For CSM-Choudhury, the initial potential leaf size was higher than for CSM-PROSAIL. However, the fractional increase in potential leaf size was higher for CSM-PROSAIL than for CSM-Choudhury. Thus, although the leaf potential size was initially smaller for CSM-PROSAIL, it had greater potential to increase as the growing season progressed. Although the model inversion procedure resulted in two different parameter sets for CSM-Choudhury and
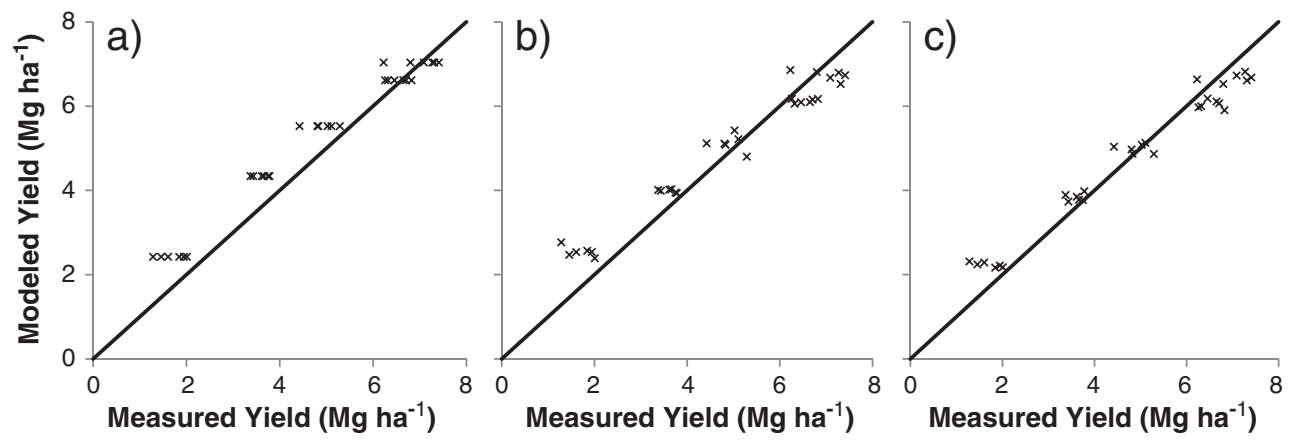

Fig. 7. Modeled versus measured wheat yield for the a) CSM alone, b) CSM-Choudhury linked model, and c) CSM-PROSAIL linked model. 
Table 5

Treatment means for the optimized leaf area growth parameters (LA1S, LAFV, and LAFR) from inversion of CSM-PROSAIL. Letters indicate statistically significant groups at the 0.05 significance level. Results for LAFV and LAFR are identical, because we linked these parameters in the PEST optimization.

\begin{tabular}{llll}
\hline & LA1S & LAFV & LAFR \\
\hline Cultivar & & & \\
Duraking & $0.868 \mathrm{a}$ & $0.550 \mathrm{a}$ & $0.550 \mathrm{a}$ \\
Topper & $0.726 \mathrm{a}$ & $0.861 \mathrm{~b}$ & $0.861 \mathrm{~b}$ \\
Kronos & $0.935 \mathrm{a}$ & $0.553 \mathrm{a}$ & $0.553 \mathrm{a}$ \\
Havasu & $0.683 \mathrm{a}$ & $0.746 \mathrm{ab}$ & $0.746 \mathrm{ab}$ \\
Orita & $0.772 \mathrm{a}$ & $0.662 \mathrm{ab}$ & $0.662 \mathrm{ab}$ \\
Ocotillo & $0.591 \mathrm{a}$ & $0.842 \mathrm{~b}$ & $0.842 \mathrm{~b}$ \\
Nitrogen rate & & & \\
N1 & $0.536 \mathrm{a}$ & $1.285 \mathrm{a}$ & $1.285 \mathrm{a}$ \\
N2 & $0.672 \mathrm{ab}$ & $0.589 \mathrm{~b}$ & $0.589 \mathrm{~b}$ \\
N3 & $0.849 \mathrm{ab}$ & $0.533 \mathrm{~b}$ & $0.533 \mathrm{~b}$ \\
N4 & $0.809 \mathrm{ab}$ & $0.565 \mathrm{~b}$ & $0.565 \mathrm{~b}$ \\
N5 & $0.946 \mathrm{~b}$ & $0.541 \mathrm{~b}$ & $0.541 \mathrm{~b}$ \\
\hline
\end{tabular}

CSM-PROSAIL (Table 6), the simulation result for LAI was essentially the same (Fig. 3, Table 3). This is an example of equifinality. Future work should focus on refining the optimization protocol to minimize this kind of problem. For example, the choice of parameters to optimize, the upper and lower limits for these parameters, the type of remote sensing information used, and the dates of observations relative to crop growth stage are all factors that could influence the performance of the optimization and lead to nonuniqueness of parameter estimates.

\subsection{Observation availability}

Maximizing the number of remote sensing observations did not lead to the best crop property estimates from model inversion procedures. Results of the genetic algorithm demonstrated that only four and two observations were needed to optimize the LAI simulation with CSM-Choudhury and CSM-PROSAIL, respectively. For CSMChoudhury, the four optimum observations were collected at 77, 97, 113 , and 125 days after planting. These dates corresponded to wheat development from terminal spikelet to the beginning of grain fill on approximately a two week basis. At 77 days after planting, the wheat crop was at terminal spikelet with approximately seven leaves initiated. Ninety-seven and 113 days after planting roughly marked maximum vegetative growth and anthesis (flowering), respectfully. At 125 days after planting, the wheat had just begun filling grain. For CSM-PROSAIL, the two observations required for optimum

\section{Table 6}

Treatment means for the optimized leaf area growth parameters (LA1S, LAFV, and LAFR) resulting from inversion of both the CSM-Choudhury and CSM-PROSAIL models. Letters indicate statistically significant groups at the 0.05 significance level. Results for LAFV and LAFR are identical, because we linked these parameters in the PEST optimization.

\begin{tabular}{llll}
\hline & LA1S & LAFV & LAFR \\
\hline $\begin{array}{l}\text { Model } \\
\text { CSM-Choudhury } \\
\text { CSM-PROSAIL }\end{array}$ & $1.121 \mathrm{a}$ & $0.437 \mathrm{a}$ & $0.437 \mathrm{a}$ \\
Cultivar & $0.762 \mathrm{~b}$ & $0.703 \mathrm{~b}$ & $0.703 \mathrm{~b}$ \\
Duraking & & & \\
Topper & $1.048 \mathrm{a}$ & $0.440 \mathrm{a}$ & $0.440 \mathrm{a}$ \\
Kronos & $0.913 \mathrm{a}$ & $0.675 \mathrm{a}$ & $0.675 \mathrm{a}$ \\
Havasu & $1.112 \mathrm{a}$ & $0.461 \mathrm{a}$ & $0.461 \mathrm{a}$ \\
Orita & $0.807 \mathrm{a}$ & $0.619 \mathrm{a}$ & $0.619 \mathrm{a}$ \\
Ocotillo & $0.903 \mathrm{a}$ & $0.554 \mathrm{a}$ & $0.554 \mathrm{a}$ \\
Nitrogen rate & $0.866 \mathrm{a}$ & $0.669 \mathrm{a}$ & $0.669 \mathrm{a}$ \\
N1 & & & \\
N2 & $0.927 \mathrm{a}$ & $0.767 \mathrm{a}$ & $0.767 \mathrm{a}$ \\
N3 & $0.870 \mathrm{a}$ & $0.481 \mathrm{a}$ & $0.481 \mathrm{a}$ \\
N4 & $1.065 \mathrm{a}$ & $0.484 \mathrm{a}$ & $0.484 \mathrm{a}$ \\
N5 & $0.902 \mathrm{a}$ & $0.549 \mathrm{a}$ & $0.549 \mathrm{a}$ \\
\hline
\end{tabular}

LAI simulations were collected at 77 and 105 days after planting, thus both models required an observation at 77 days after planting. This day corresponded to roughly half of maximum LAI for the high nitrogen rate treatment (Fig. 8). At 105 days after planting, the wheat was one week beyond peak vegetative growth and one week prior to anthesis. Clearly, remote sensing observations at midvegetative and maximum vegetative growth were key. Saturation of NDVI early in the season was a likely reason for CSM-Choudhury requiring twice as many remote sensing observations as CSM-PROSAIL. At 77 days after planting, the NDVI had already reached $94 \%$ of its maximum value, while LAI had only reached $51 \%$ of its maximum (Fig. 8). The additional information available in the full spectrum scan permitted fewer required remote sensing observations for model inversion as compared to NDVI.

\subsection{Spectral considerations}

Inversion of CSM-PROSAIL offered several advantages as compared to inversion of CSM-Choudhury. Although the results were not substantially different, CSM-PROSAIL estimates of LAI, plant nitrogen, and yield were closer to measurements than that for CSM-Choudhury (Table 3). Only for canopy weight were the CSM-PROSAIL estimates worse than CSM-Choudhury. Also as mentioned above, CSM-PROSAIL inversion led to statistically significant estimates of leaf area growth potential among wheat cultivars (Table 5), where as CSM-Choudhury did not (Table 4). Since leaf area growth potentials are cultivar parameters in the CSM model, ability to estimate differences among several crop cultivars using model inversion is a positive finding. Finally, CSMPROSAIL required half as many remote sensing observations as CSMChoudhury to achieve these better results. These examples demonstrate positive advantages of using full spectrum data for model inversion as compared to simple vegetation indices.

Despite this favorable result, there is still need for further investigation into the nature of the CSM-PROSAIL linkage as well as the protocol for using hyperspectral information for model inversion. For example, we have previously discussed the fact that CSM simulates plant nitrogen content $\left(\mathrm{g} \mathrm{cm}^{-2}\right)$ whereas PROSAIL requires $C_{a b}$ $\left(\mu \mathrm{g} \mathrm{cm}^{-2}\right)$. The two quantities are related (Evans, 1983), but this aspect of the linkage is not as explicit as that for LAI. There is also opportunity to expand the number of parameters that CSM provides to PROSAIL. For simplicity, we constrained the CSM-PROSAIL linkage to the two parameters for which we had field measurements. However, CSM could likely also provide PROSAIL an estimate of leaf dry

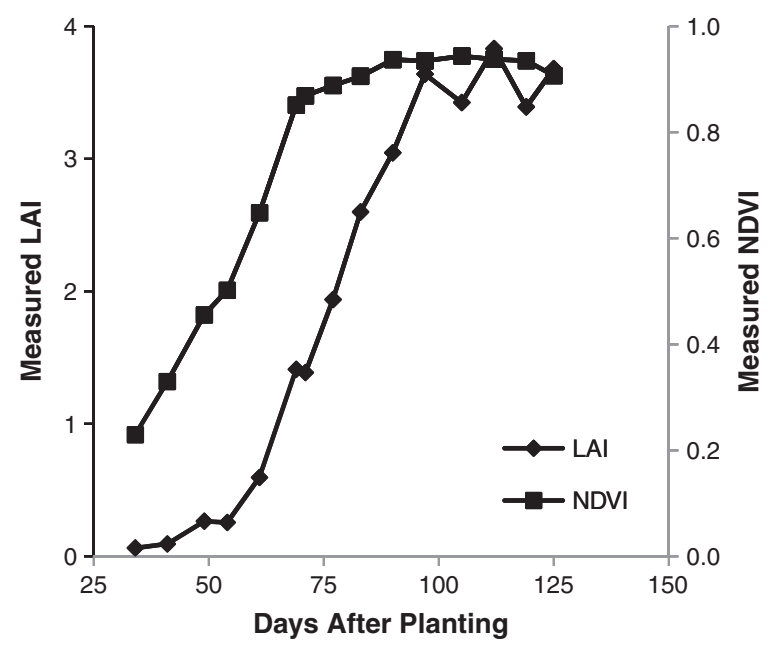

Fig. 8. Average measured leaf area index (LAI) with the Li-Cor LAI-2000 Plant Canopy Analyzer and average measured normalized difference vegetation index (NDVI) with the GER 1500 spectroradiometer for the highest nitrogen rate treatment over the growing season. 
matter content $\left(C_{m} ; \mathrm{g} \mathrm{cm}^{-2}\right)$, and it may be possible to estimate leaf water content or leaf inclination angle from CSM's water stress simulation. CSM-PROSAIL model inversions may also be enhanced by using a strategic subset of spectral wavelengths in the PEST optimization or by incorporating a multivariate analysis of the spectral data prior to model inversion. Future work should focus on identifying key spectral wavelengths and assessing how various spectral band combinations would influence the inversion process.

\section{Conclusions}

Several past studies have shown that model inversion based on remote sensing observations can improve estimates of LAI and crop yield. Many of these studies focused on using simple vegetation indices for inversion of simple crop growth models. We show that model inversion can also be advantageous through linkages of more complex radiative transfer and ecophysiological models, such as PROSAIL and the DSSAT-CSM respectively. Inversion of these linked models based on remote sensing observations can lead to better estimates of leaf area index (LAI), canopy weight, plant nitrogen content, and crop yield as compared to either model alone. In particular, we highlight that our model inversion approaches were able to improve simulations of the plant nitrogen balance and leaf chlorophyll content, since most earlier studies have focused on LAI and yield rather than nitrogen.

A minimum of two remote sensing observations provided optimum model inversions for some cases. One observation at midvegetative growth and another between maximum vegetative growth and anthesis was enough to optimize LAI for the inversion of CSMPROSAIL based on full spectrum data. However, additional measurements may be required if simpler vegetation indices are used. Since our remote sensing data set was limited to 16 dates, there is opportunity for further investigation into how timing and availability of observations affect the model inversion performance.

Use of hyperspectral observations offers several advantages for model inversion, including better estimation of most crop biophysical properties, statistically different cultivar parameter estimates, and fewer required remote sensing observations. Further efforts are needed to understand how to optimally utilize the hyperspectral data, particularly how selection of alternative waveband combinations might affect the model inversion performance.

Future studies should also focus on exploration of alternative protocol for model inversion. We chose to maintain simplicity by adjusting only three parameters that govern the leaf area growth process. However, LAI is certainly also affected by the parameters that govern the crop development simulation. A more comprehensive model inversion procedure might independently adjust parameters that affect both the magnitude and the timing of LAI growth. Better approaches for setting the upper and lower bounds on these parameters are also needed, since model inversion performance can be quite sensitive to this.

\section{Acknowledgments}

The authors acknowledge the USDA-ARS-ALARC technicians (Suzette Maneely and Kathy Johnson), Maricopa Agricultural Center technicians (Ken Randolph and Cory Runyon), University of Arizona graduate student (Ruth Asiimwe), and the day crews for their help with field and laboratory work. The authors also acknowledge the Ar- izona Grain Research and Promotion Council for contributing funds for this research.

\section{References}

Botha, E., Leblon, B., Zebarth, B., \& Watmough, J. (2007). Non-destructive estimation of potato leaf chlorophyll from canopy hyperspectral reflectance using the inverted PROSAIL model. International Journal of Applied Earth Observation and Geoinformation, 9(4), 360-374.

Botha, E., Leblon, B., Zebarth, B., \& Watmough, J. (2010). Non-destructive estimation of wheat leaf chlorophyll content from hyperspectral measurements through analytical model inversion. International Journal of Remote Sensing, 31(7), 1679-1697.

Choudhury, B. J., Ahmed, N. U., Idso, S. B., Reginato, R. J., \& Daughtry, C. S. T. (1994). Relations between evaporation coefficients and vegetation indexes studied by model simulations. Remote Sensing of Environment, 50(1), 1-17.

Combal, B., Baret, F., Weiss, M., Trubuil, A., Macé, D., Pragnère, A., et al. (2003). Retrieval of canopy biophysical variables from bidirectional reflectance using prior information to solve the ill-posed inverse problem. Remote Sensing of Environment, 84(1), $1-15$.

Davies, E. (2009). The application of machine vision to food and agriculture: A review. Imaging Science Journal, 57(4), 197-217.

Doherty, J. (2005). PEST: Model-independent parameter estimation User manual (5th edition). Brisbane, Australia: Watermark Numerical Computing.

Evans, J. R. (1983). Nitrogen and photosynthesis in the flag leaf of wheat (Triticum aestivum L.). Plant Physiology, 72, 297-302.

Goel, N., \& Strebel, D. (1983). Inversion of vegetation canopy reflectance models for estimating agronomic variables. I. Problem definition and initial results using the Suits model. Remote Sensing of Environment, 13(6), 487-507.

Green, R. O., Eastwood, M. L., Sarture, C. M., Chrien, T. G., Aronsson, M., Chippendale, B. J., et al. (1998). Imaging spectroscopy and the Airborne Visible/Infrared Imaging Spectrometer (AVIRIS). Remote Sensing of Environment, 65(3), 227-248.

Guerif, M., \& Duke, C. L. (2000). Adjustment procedures of a crop model to the site specific characteristics of soil and crop using remote sensing data assimilation. Agriculture Ecosystems \& Environment, 81(1), 57-69.

Jacquemoud, S. (1993). Inversion of the PROSPECT + SAIL canopy reflectance model from AVIRIS equivalent spectra: Theoretical study. Remote Sensing of Environment, 44(2-3), 281-292.

Jacquemoud, S., Baret, F., Andrieu, B., Danson, F., \& Jaggard, K. (1995). Extraction of vegetation biophysical parameters by inversion of the PROSPECT +SAIL models on sugar beet canopy reflectance data. Application to TM and AVIRIS sensors. Remote Sensing of Environment, 52(3), 163-172.

Jacquemoud, S., Verhoef, W., Baret, F., Bacour, C., Zarco Tejada, P. J., Asner, G. P., et al. (2009). PROSPECT + SAIL models: A review of use for vegetation characterization. Remote Sensing of Environment, 113(Suppl. 1), S56-S66.

Jones, J. W., Hoogenboom, G., Porter, C. H., Boote, K. J., Batchelor, W. D., Hunt, L. A., et al. (2003). The DSSAT cropping system model. European Journal of Agronomy, 18(3-4), 235-265.

Koetz, B., Baret, F., Poilvé, H., \& Hill, J. (2005). Use of coupled canopy structure dynamic and radiative transfer models to estimate biophysical canopy characteristics. Remote Sensing of Environment, 95(1), 115-124.

Luo, Y., Weng, E., Wu, X., Gao, C., Zhou, X., \& Zhang, L. (2009). Parameter identifiability, constraint, and equifinality in data assimilation with ecosystem models. Ecological Applications, 19(3), 571-574.

Maas, S. J. (1988). Using satellite data to improve model estimates of crop yield. Agronomy Journal, 80(4), 655-662.

Prevot, L., Chauki, H., Troufleau, D., Weiss, M., Baret, F., \& Brisson, N. (2003). Assimilating optical and radar data into the STICS crop model for wheat. Agronomie, 23(4), 297-303.

Reda, I., \& Andreas, A. (2004). Solar position algorithm for solar radiation applications. Solar Energy, 76(5), 577-589.

Rodriguez, J., Ustin, S., \& Riaño, D. (2011). Contributions of imaging spectroscopy to improve estimates of evapotranspiration. Hydrological Processes, 25(26), 4069-4081.

Schaap, M. G., Leij, F. J., \& van Genuchten, M. T. (2001). ROSETTA: A computer program for estimating soil hydraulic parameters with hierarchical pedotransfer functions. Journal of Hydrology, 251(3-4), 163-176.

Thorp, K. R., Hunsaker, D. J., \& French, A. N. (2010). Assimilating leaf area index estimates from remote sensing into the simulations of a cropping systems model. Transactions of the ASABE, 53(1), 251-262.

Wiegand, C. L., Richardson, A. J., \& Kanemasu, E. T. (1979). Leaf area index estimates for wheat from LANDSAT and their implications for evapotranspiration and crop modeling. Agronomy Journal, 71(2), 336-342.

Xie, Y. C., Sha, Z. Y., \& Yu, M. (2008). Remote sensing imagery in vegetation mapping: A review. Journal of Plant Ecology, 1(1), 9-23.

Yang, Y., \& Ling, P. (2004). Improved model inversion procedure for plant water status assessment under artificial lighting using PROSPECT+SAIL. Transactions of the ASAE, 47(5), 1833-1840. 